\title{
Dynamic Thiol/Disulphide Homeostasis in Children and Adolescents with Non-Autoimmune Subclinical Hypothyroidism
}

\author{
Seyit Ahmet Uçaktürk ${ }^{a} \quad$ Murat Alışık $^{b}$ Çağatay Uğur ${ }^{c}$ Selin Elmaoğulları ${ }^{a}$ \\ Eda Mengen ${ }^{a}$ Özcan Erel ${ }^{d}$
}

a Department of Pediatric Endocrinology, Ankara Children's Hematology and Oncology Training Hospital, Ankara,

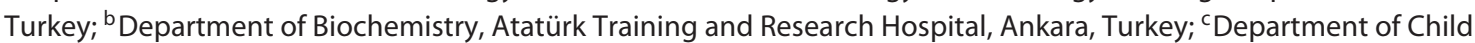
and Adolescent Psychiatry, Ankara, Turkey; ${ }^{d}$ Department of Biochemistry, Yıldırım Beyazıt University, School of Medicine, Ankara, Turkey

\section{Significance of the Study}

- In this study, we detected that dynamic thiol/disulphide homeostasis, which is an indicator of oxidative stress, did not change in children with non-autoimmune subclinical hypothyroidism (SHT). Hence, this study provided further evidence that SHT is a benign condition in children and that $\mathrm{L}_{-} \mathrm{T}_{4}$ treatment is not necessary.

\section{Keywords}

Thiol/disulphide homeostasis · Subclinical hypothyroidism · Oxidative stress

\begin{abstract}
Objective: To evaluate the thiol/disulphide homeostasis in children with non-autoimmune subclinical hypothyroidism (SHT). Subjects and Methods: Thiol/disulphide homeostasis, involving native thiol ( $\mathrm{SH})$, disulphide (SS), and total thiol $(\mathrm{SS}+\mathrm{SH})$, was evaluated in 60 children and adolescents who were negative for thyroid auto-antibodies (anti-thyroid peroxidase, anti-thyroglobulin) and had a thyroid-stimulating hormone (TSH) value of $>5 \mathrm{mIU} / \mathrm{L}$, and in $40 \mathrm{sex}$ - and agematched healthy control subjects who were negative for thyroid autoantibodies and had normal TSH levels. Lipid profiles and urine iodine levels were also determined. Results:
\end{abstract}

$\mathrm{SH}(466 \pm 32.8$ vs. $462 \pm 32.1 \mu \mathrm{mol} / \mathrm{L} p=0.59), \mathrm{SH}+\mathrm{SS}(508$ \pm 34.0 vs. $506 \pm 32.7 \mu \mathrm{mol} / \mathrm{L}, p=0.81)$, SS ( $21 \pm 5.5$ vs. $22 \pm$ $5.8 \mu \mathrm{mol} / \mathrm{L}, p=0.41), \mathrm{SS} / \mathrm{SH}(4.5 \pm 1.2$ vs. $4.8 \pm 1.3 \%, p=0.36)$, $\mathrm{SS} / \mathrm{SH}+\mathrm{SS}(4.1 \pm 1.0$ vs. $4.3 \pm 1.1 \%, p=0.36)$ and SH/SH + SS $(91 \pm 2.1$ vs. $91 \pm 2.1 \%, p=0.31)$ levels were similar in children with SHT and control subjects ( $p>0.05$ ). There was no difference between total cholesterol, triglyceride, and low-density lipoprotein levels in SHT patients and controls. No difference was detected between the patients with or without iodine deficiency in the SHT group in terms of thiol/disulphide homeostasis parameters. Conclusion: The status of dynamic thiol/disulphide homeostasis did not change in children and adolescents with non-autoimmune SHT. Future studies are needed for the evaluation of oxidative stress in patients with long-standing non-autoimmune SHT.

(c) 2018 The Author(s)

Published by S. Karger AG, Basel

\begin{tabular}{|c|c|c|}
\hline KARGER & $\begin{array}{l}\text { (0) } 2018 \text { The Author(s) } \\
\text { Published by S. Karger AG, Basel }\end{array}$ & $\begin{array}{l}\text { Karger } \\
\text { Open access }\end{array}$ \\
\hline $\begin{array}{l}\text { E-Mail karger@karger.com } \\
\text { www.karger.com/mpp }\end{array}$ & $\begin{array}{l}\text { This is an Open Access article licensed } y \\
\text { Attribution-NonCommercial-4.0 Intern } \\
\text { (http://www.karger.com/Services/Open } \\
\text { the online version of the article only. } \\
\text { commercial purposes requires written p }\end{array}$ & $\begin{array}{l}\text { er the Creative Commons } \\
\text { onal License (CC BY-NC) } \\
\text { essLicense), applicable to } \\
\text { age and distribution for } \\
\text { nission. }\end{array}$ \\
\hline
\end{tabular}

S. Ahmet Uçaktürk

Department of Pediatric Endocrinology

Ankara Children's Hematology and Oncology Training Hospital

Şehit Ömer Halisdemir Caddesi, Kurtdereli Sokak, No. 10, TR-06110 Ankara (Turkey)

E-Mail uahmet77@yahoo.com 


\section{Introduction}

Subclinical hypothyroidism (SHT) is a biochemical condition characterized by increased serum levels of thyroid-stimulating hormone (TSH) above the upper limit of the reference range, with normal serum free thyroxine $\left(\mathrm{FT}_{4}\right)$ concentrations. SHT in children is often a benign and remitting condition with a low risk of progression toward overt hypothyroidism [1]. The negative effects of SHT on the health of children are controversial. The role of SHT on atherosclerotic disease is still debated [1]. Some evidence suggest that long-term mild TSH elevation might be related to subtle proatherogenic abnormalities such as mild hyperlipidemia and an elevated atherogenic index [2]. Thyroid hormones have been shown to affect the synthesis and degradation of antioxidant proteins, vitamins, and enzymes [3]. Hypothyroidism leads to oxidative stress (OS) via both an increased production of free radicals and a reduced antioxidant defense capacity [4]. A short-term and rapid increase in TSH level may cause OS and low-grade inflammation. It has been reported that TSH induces the secretion of inflammatory cytokines such as tumor necrosis factor (TNF)- $\alpha$ and interleukin (IL)-6 in vitro [5]. A high TSH concentration is also associated with increased mobilization of body fat reserves [6].

OS occurs as a result of the increased production of free radicals and reactive oxygen species (ROS) and/or reduced antioxidant defense mechanisms [7]. It damages intracellular and membrane-associated proteins, carbohydrates and lipids, affects enzyme and neurotransmitter receptor functions, and causes DNA mutations [7]. ROS play a crucial role in the genesis of atherosclerosis inducing vascular smooth-muscle cell proliferation, vascular inflammation, the oxidation of low-density lipoprotein cholesterol (LDL-C), and the reduction of nitric oxide bioavailability [8]. Thiols are important antioxidant buffers because they contain sulfhydryl groups which reduce oxidant molecules, thereby protecting the organism from oxidative damage [9]. They are converted to disulphides during this reaction, and can be reconverted into thiol groups, and so a dynamic thiol balance is established. Thiol/disulphide homeostasis is regarded as an indicator of OS $[9,10]$. OS markers have been found to be increased in patients with autoimmune SHT [11-13].

Hashimoto thyroiditis is a chronic inflammatory and autoimmune disease [11]. Abnormal thiol/disulphide homeostasis plays a pivotal role in the pathophysiology of many chronic inflammatory diseases [14-16]. Increased OS may be related to autoimmunity in patients with
Hashimoto thyroiditis [11]. The objective of this study was to evaluate dynamic thiol/disulphide homeostasis in children and adolescents with non-autoimmune SHT.

\section{Subjects and Methods}

Before the study, all SHT patients and control subjects underwent a clinical evaluation by measuring their height and weight. Body weight measurements were conducted after a 8-h fasting period, barefoot, and with their daily clothes on and height was measured with the patient barefoot with the Seca 274 Stadiometer (Hamburg, Germany) with $1 \mathrm{~mm}$ accuracy. The BMI and height standard deviation scores (SDS) were calculated using published reference values for healthy Turkish children [17].

Sixty patients with non-autoimmune SHT and 40 healthy subjects were included in the study. The patient group consisted of patients with negative thyroid autoantibody (anti-thyroglobulin antibody [anti-Tg] and anti-thyroid peroxidase antibody [anti$\mathrm{TPO}]$ ), an absence of palpable goiter or symptoms related to hypothyroidism from the time of SHT identification to the beginning of the study, a TSH level $>5 \mathrm{mIU} / \mathrm{L}$, and an $\mathrm{FT}_{4}$ value within the normal range of reference values. Patients with a high TSH were evaluated once more after 3 months, and were included in the study if their TSH levels were still elevated. The control group consisted of sex- and age-matched healthy subjects who were negative for thyroid autoantibodies and whose thyroid function tests were normal. None of the controls had a personal or family history of thyroid disease or goiter upon examination.

Exclusion criteria for both groups were the existence of any renal, hepatic, cardiac, endocrine, autoimmune, infectious, musculoskeletal, or malignant diseases, any previous irradiation in the neck region, any form of vitamin supplementation, previous or current thyroid diseases, previous ${\mathrm{L}-\mathrm{T}_{4}}_{4}$ replacement therapy, the use of drugs that might interfere with thyroid function, chromosomal and genetic syndromes, being born premature or small for gestational age, familial hypercholesterolaemia, or familial cardiac disease.

Blood samples were taken from patients and control subjects after $8 \mathrm{~h}$ of fasting. TSH, $\mathrm{FT}_{4}$, anti-TPO, and anti-Tg were measured with an immunoassay using a Beckman Coulter DX1800 (Brea, CA, USA), and triglycerides (TG), total cholesterol (TC), and high-density lipoprotein cholesterol (HDL-C) were measured photometrically with a Beckman Coulter AU680. Urine iodine was measured in the first morning urine samples with a Shimadzu LCMS-8040 (Kyoto, Japan) device and the LC-MS/MS method in patients with SHT. Mild iodine deficiency was considered as 50-99 $\mu \mathrm{g} / \mathrm{L}$, moderate as $20-49 \mu \mathrm{g} / \mathrm{L}$, and severe as $<20 \mu \mathrm{g} / \mathrm{L}$ [18].

Blood specimens were collected between 8:00 and 10:00 a.m. following $8 \mathrm{~h}$ of fasting, for the detection of thiol/disulphide homeostasis parameters. Samples were then immediately centrifuged for $10 \mathrm{~min}$ at $1,500 \mathrm{rpm}$ to separate plasma and serum. Serum specimens were stored at $-80^{\circ} \mathrm{C}$ until all samples had been collected. All thiol/disulphide homeostasis parameters were studied from the same samples. Serum dynamic thiol/disulphide homeostasis was determined with the spectrophotometric method described by Erel and Neselioglu [19] using an automated clinical chemistry analyzer (Roche, Cobas 501, Mannheim, Germany). Sodium borohydride is the essential agent in this method that is used 
Table 1. Clinical and laboratory characteristics of patients with subclinical hypothyroidism and control subjects

\begin{tabular}{|c|c|c|c|}
\hline & Patients $(n=60)$ & Controls $(n=40)$ & $p$ value \\
\hline Age, years & $9.7 \pm 3.5$ & $10.8 \pm 2.5$ & 0.09 \\
\hline $\operatorname{Sex}(\mathrm{F} / \mathrm{M}), n(\%)$ & $27 / 33(45 / 55)$ & $18 / 22(45 / 55)$ & 0.51 \\
\hline BMI & $0.71 \pm 1.03$ & $0.04 \pm 0.71$ & 0.89 \\
\hline Height & $0.009 \pm 1.16$ & $-0.20 \pm 0.84$ & 0.32 \\
\hline $\mathrm{TC}, \mathrm{mg} / \mathrm{dL}$ & $159.06 \pm 26.22$ & $151.29 \pm 27.74$ & 0.30 \\
\hline $\mathrm{LDL}-\mathrm{C}, \mathrm{mg} / \mathrm{dL}$ & $88.44 \pm 22.31$ & $82.56 \pm 19.22$ & 0.34 \\
\hline $\mathrm{TG}, \mathrm{mg} / \mathrm{dL}$ & $88.76 \pm 44.12$ & $90.78 \pm 27.44$ & 0.85 \\
\hline $\mathrm{HDL}-\mathrm{C}, \mathrm{mg} / \mathrm{dL}$ & $52.31 \pm 12.96$ & $50.00 \pm 11.91$ & 0.50 \\
\hline TSH (min.-max.), mIU/L & $6.54 \pm 1.16(5.30-9.50)$ & $2.58 \pm 1.02(0.73-4.30)$ & $<0.001$ \\
\hline $\mathrm{FT}_{4}, \mathrm{ng} / \mathrm{dL}$ & $0.92 \pm 0.11$ & $0.93 \pm 0.08$ & 0.71 \\
\hline
\end{tabular}

TC, total cholesterol; LDL-C, low-density lipoprotein cholesterol; HDL-C, high-density lipoprotein cholesterol; TG, triglyceride; TSH, thyroid-stimulating hormone; $\mathrm{FT}_{4}$, free thyroxine.

Table 2. Thiol/disulphide homeostasis parameters in patients with subclinical hypothyroidism and control subjects

\begin{tabular}{lccc}
\hline & $\begin{array}{c}\text { Patients } \\
(n=60)\end{array}$ & $\begin{array}{l}\text { Control subjects } \\
(n=40)\end{array}$ & $p$ value \\
\hline Native thiol, $\mu \mathrm{mol} / \mathrm{L}$ & $466 \pm 32.8$ & $462 \pm 32.1$ & 0.59 \\
Total thiol, $\mu \mathrm{mol} / \mathrm{L}$ & $508 \pm 34.0$ & $506 \pm 32.7$ & 0.81 \\
Disulphide, $\mu \mathrm{mol} / \mathrm{L}$ & $21 \pm 5.5$ & $22 \pm 5.8$ & 0.41 \\
Disulphide/native thiol, \% & $4.5 \pm 1.2$ & $4.8 \pm 1.3$ & 0.36 \\
Disulphide/total thiol, \% & $4.1 \pm 1.0$ & $4.3 \pm 1.1$ & 0.36 \\
Native thiol/total thiol, \% & $91 \pm 2.1$ & $91 \pm 2.1$ & 0.34
\end{tabular}

to reduce dynamic bonds to functional thiol groups. To prevent extra reduction of 5, $5^{\prime}$-dithiobis-2- nitrobenzoic acid, unused sodium borohydride was removed by the addition of formaldehyde. The total thiol content of the sample was measured using a modified Ellman reagent. The dynamic disulphide amount was calculated by determining half of the difference between the total thiol and the native thiol. The data obtained were determined as total thiol, native thiol, disulphide, disulphide/total thiol, disulphide/ native thiol, and native thiol/total thiol levels.

This study was performed at the Ankara Children's Hematology and Oncology Training and Research Hospital between June 2016 and April 2017. The thiol/disulphide homeostasis parameters were studied in the Yıldırım Beyazıt University Biochemistry Laboratory. The study was conducted in accordance with the Declaration of Helsinki and was approved by the hospital research ethics committee. Informed consent was obtained from all participants and their parents before the study.

\section{Statistical Analysis}

SPSS for Windows v17.0 was used to evaluate the data. The Student $t$ test was used to compare variables fit for normal distribution, and the Mann-Whitney $\mathrm{U}$ test to compare variables not fit for normal distribution. Correlation analyses were performed with the Pearson correlation test. Results were expressed as mean \pm standard deviation and statistical significance was set at $p<0.05$.

\section{Results}

Clinical and laboratory data of the patients and control subjects are presented in Table 1. Age, gender, BMI SDS, and height SDS were similar in the patient and control groups. There was a significant difference in TSH levels between the groups $(6.54 \pm 1.16$ vs. $2.58 \pm 1.02 \mathrm{mIU} / \mathrm{L}$, respectively, $p<0.001)$. TC, LDL-C, TG, and HDL-C levels were similar in both groups. Levels of native thiol $(\mathrm{SH})$, total thiol $(\mathrm{SH}+\mathrm{SS})$, disulphide (SS), disulphide/ native thiol (SS/SH), disulphide/total thiol (SS/SH + SS) and native thiol/total thiol $(\mathrm{SH} / \mathrm{SH}+\mathrm{SS})$ were similar in both groups. The thiol/disulphide homeostasis variables of the patients and control subjects are shown in Table 2. 
Table 3. Comparison of thiol/disulphide homeostasis parameters of subclinical hypothyroidism patients

\begin{tabular}{lccc}
\hline & $\begin{array}{l}\text { Patients with an iodine } \\
\text { deficiency }(n=19)\end{array}$ & $\begin{array}{l}\text { Patients with a normal } \\
\text { iodine level }(n=41)\end{array}$ & $p$ value \\
\hline Native thiol, $\mu \mathrm{mol} / \mathrm{L}$ & $467.5 \pm 28.1$ & $462.6 \pm 41.9$ & 0.60 \\
Total thiol, $\mu \mathrm{mol} / \mathrm{L}$ & $508.9 \pm 31.3$ & $507.2 \pm 40.8$ & 0.85 \\
Disulphide, $\mu \mathrm{mol} / \mathrm{L}$ & $20.7 \pm 5.6$ & $22.3 \pm 5.4$ & 0.31 \\
Disulphide/native thiol, \% & $4.4 \pm 1.2$ & $4.8 \pm 1.3$ & 0.22 \\
Disulphide/total thiol, \% & $4.0 \pm 1.0$ & $4.4 \pm 1.1$ & 0.22 \\
Native thiol/total thiol, \% & $91.8 \pm 2.0$ & $91.1 \pm 2.2$ & 0.22 \\
\hline
\end{tabular}

No correlation was found between age, BMI SDS, TSH, lipid levels, and thiol/disulphide variables.

Iodine deficiency was detected in 19/60 (31\%) patients with SHT, 5 (26\%) of whom had moderate iodine deficiency $(20-49 \mu \mathrm{g} / \mathrm{L})$ and $14(74 \%)$ mild iodine deficiency $(20-49 \mu \mathrm{g} / \mathrm{L})$. There was no difference between the OS parameters of patients with and without iodine deficiency $(p>0.05)$ (Table 3$)$.

\section{Discussion}

In this study, we demonstrated that thiol/disulphide homeostasis does not change in children with SHT. Previous studies reported increased OS in adult patients with SHT [11-13]; these studies either included only patients with autoimmune hypothyroidism [11-13] or the presence of autoimmune thyroiditis was not reported [20,21]. Hashimoto thyroiditis is a chronic inflammatory autoimmune disease. Autoimmunity and inflammation may cause the production of oxygen radicals, or oxidant radicals may trigger inflammation and autoimmunity [11]. On the other hand, OS may account for the pathogenesis of autoimmune thyroid disease $[22,23]$. Exposure to high doses of hydrogen peroxide $\left(\mathrm{H}_{2} \mathrm{O}_{2}\right)$ and/or the impairment of antioxidant systems can lead to the functional and morphological deterioration of Tg and TPO and a change in their antigenic properties [22]. The accumulation of ROS plays a role in the initiation of inflammatory response in follicular cells via the increase of intercellular adhesion molecule 1 (ICAM-1) [23]. A positive correlation was reported between anti-TPO level, SS/SH, SS/SH + SS ratio and SS level in adults with SHT [11]. In one study, a positive correlation between anti-TPO levels and OS marker was found in children (23 with overt hypothyroidism and 9 with SHT) with autoimmune thyroiditis [24]. OS in euthyroid adult patients with autoimmune thyroiditis is also elevated in association with the anti-Tg level [25]. OS has also been reported to be high in hypothyroid patients with positive anti-TPO compared to those with negative anti-TPO [26]. Thiols are organic compounds containing sulfhydryl groups, and they play critical roles in the coordination of antioxidant defense systems and the protection of the cells against OS [9]. Plasma thiol pools are predominantly composed of protein thiol and albumin thiols. Whereas SH + SS contains reduced and unreduced thiols, SH refers only to unreduced thiols. Thiol groups are converted reversibly to disulphide bond structures by oxidant molecules [10]. These disulphide bonds are reversible and are the earliest sign of protein oxidation [27]. Disulphide bonds are rereduced to thiol groups by antioxidants, thereby maintaining thiol/disulphide homeostasis $[9,10]$.

In our study, there was no difference between patients and healthy control subjects in terms of lipid levels. Thyroid hormones lower cholesterol levels by decreasing the intestinal absorption of cholesterol and increasing hepatic cholesterol synthesis and the levels of LDL receptors. This reduction of receptor levels leads to a decrease in LDL-C clearance and an increase in serum levels [28]. Mild dyslipidemia has been documented among children with untreated subclinical hypothyroidism [4]. While the HDL-C level in children with untreated, long-standing non-autoimmune SHT was lower than healthy subjects, TC, TG, and LDL-C levels were not significantly different in patients and controls [2]. Serum TG levels and LDL oxidizability might be effected in SHT but the available information on this subject is controversial [28]. Although LDL-C levels have been found to be elevated in adult patients with SHT [20], no change in LDL-C levels were reported [12, 25].

Iodine is a part of thyroid hormone molecules and has been reported to induce anti-OS enzymes such as superoxide dismutase or act indirectly as an antioxidant. In diabetic patients supplemented with iodine, the superoxidase level was decreased and antioxidant enzymes such as plasma catalase and glutathione peroxidase were in-
Uçaktürk/Alışı/Uğur/Elmaoğulları/ Mengen/Erel 
creased, while erythrocyte glutathione peroxidase and the malonyl dialdehyde level indicating lipid peroxidation remained unchanged [29]. In a study which reported OS parameters to be higher in pediatric patients with moderate iodine deficiency $(20-49 \mu \mathrm{g} / \mathrm{L})$ than in patients with mild iodine deficiency $(50-99 \mu \mathrm{g} / \mathrm{L})$ or normal levels, TSH and thyroid autoantibodies were not analyzed [30]. In our study there was no difference between the OS parameters of patients with and without iodine deficiency. However, in the majority of our patients (14/19) with low iodine levels, the urine iodine level was between 50 and $99 \mu \mathrm{g} / \mathrm{L}$, which could be considered as a mild deficiency.

The most significant limitation of our study was the low number of participants. Patients with elevated TSH were followed for 3 months and they were included in the study if their TSH remained elevated after 3 months. A 3 -month follow-up may not be sufficient to evaluate the presence of OS.

\section{Conclusion}

This study showed that non-autoimmune SHT did not affect the thiol/disulphide balance. Hence, non-autoimmune SHT might not cause OS in children and adolescents. Further studies in patients with long-standing TSH elevation are needed.

\section{References}

1 Salerno M, Capalbo D, Cerbone M, et al: Subclinical hypothyroidism in childhood - current knowledge and open issues. Nat Rev Endocrinol 2016;12:734-746.

2 Cerbone M, Capalbo D, Wasniewska M, et al: Cardiovascular risk factors in children with long-standing untreated idiopathic subclinical hypothyroidism. J Clin Endocrinol Metab 2014;99:2697-2703.

-3 Pereira B, Rosa LF, Safi DA, et al: Control of superoxide dismutase, catalase and glutathione peroxidase activities in rat lymphoid organs by thyroid hormones. J Endocrinol 1994 140:73-77.

4 Yilmaz S, Ozan S, Benzer F, et al: Oxidative damage and antioxidant enzyme activities in experimental hypothyroidism. Cell Biochem Funct 2003;21:325-330.

5 Zhang YJ, Zhao W, Zhu MY, et al: Thyroidstimulating hormone induces the secretion of tumor necrosis factor- $\alpha$ from $3 \mathrm{~T} 3$-L1 adipocytes via a protein kinase A-dependent pathway. Exp Clin Endocrinol Diabetes 2013;121: 488-493.

6 Varghese S, Shameena B, Oommen OV: Thyroid hormones regulate lipid peroxidation and antioxidant enzyme activities in Anabas testudineus (Bloch). Comp Biochem Physiol B Biochem Mol Biol 2001;128:165-171.

7 Guemouri L, Artur Y, Herbeth B, et al: Biological variability of superoxide dismutase, glutathione peroxidase, and catalase in blood. Clin Chem 1991;37:1932-1937.

8 Mancini A, Raimondo S, Di Segni C, et al: Thyroid hormones and antioxidant systems: focus on oxidative stress in cardiovascular and pulmonary diseases. Int J Mol Sci 2013; 14:23893-23909.

\$ Cremers CM, Jakob U: Oxidant sensing by reversible disulphide bond formation. J Biol Chem 2013;288:26489-26496.
10 Jones DP, Liang Y: Measuring the poise of thi$\mathrm{ol} /$ disulphide couples in vivo. Free Radic Biol Med 2009;47:1329-1338.

11 Ates I, Altay M, Yilmaz FM, et al: Dynamic thiol/disulfide homeostasis in patients with autoimmune subclinical hypothyroidism. Endocr Res 2016;41.343-349.

12 Öztürk Ü, Vural P, Özderya A, et al: Oxidative stress parameters in serum and low density lipoproteins of Hashimoto's thyroiditis patients with subclinical and overt hypothyroidism. Int Immunopharmacol 2012;14:349352.

13 Cebeci E, Alibaz-Oner F, Usta M, et al: Evaluation of oxidative stress, the activities of paraoxonase and arylesterase in patients with subclinical hypothyroidism. J Investig Med 2012; 60:23-28.

14 Abdali D, Samson SE, Grover AK: How effective are antioxidant supplements in obesity and diabetes? Med Princ Pract 2015;24:201-215.

15 Torun E, Gedik AH, Cakir E, et al: Serum paraoxonase 1 activity and oxidative stress in pediatric patients with pulmonary tuberculosis. Med Princ Pract 2014;23:426-431.

16 Khan I, Samson SE, Grover AK: Antioxidant supplements and gastrointestinal diseases: a critical appraisal. Med Princ Pract 2017;26: 201-217.

17 Neyzi O, Bundak R, Gökçay G, et al: Reference values for weight, height, head circumference, and body mass index in Turkish children. J Clin Res Pediatr Endocrinol 2015;7: 280-293.

18 WHO, UNICEF, ICCIDD: Assessment of Iodine Deficiency Disorders and Monitoring Their Elimination, ed 3. Geneva, World Health Organization, 2007.

19 Erel O, Neselioglu S: A novel and automated assay for thiol/disulphide homeostasis. Clin Biochem 2014;47:326-332.
20 Reddy VS, Gouroju S, Suchitra MM, et al: Antioxidant defense in overt and subclinical hypothyroidism. Horm Metab Res 2013;45: 754-758.

21 Torun AN, Kulaksizoglu S, Kulaksizoglu M, et al: Serum total antioxidant status and lipid peroxidation marker malondialdehyde levels in overt and subclinical hypothyroidism. Clin Endocrinol 200;70:469-474.

22 Duthoit C, Estienne V, Giraud A, et al: Hydrogen peroxide-induced production of a 40 $\mathrm{kDa}$ immunoreactive thyroglobulin fragment in human thyroid cells: the onset of thyroid autoimmunity? Biochem J 2001;360:557-562.

23 Burek CL, Rose NR: Autoimmune thyroiditis and ROS. Autoimmun Rev 2008;7:530-537.

24 Metwalley KA, Farghaly HS, Saad K, et al: Oxidative status in children and adolescents with autoimmune thyroiditis. Clin Exp Med 2016; 16:571-575.

25 Baser H, Can U, Baser S, et al: Assessment of oxidative status and its association with thyroid autoantibodies in patients with euthyroid autoimmune thyroiditis. Endocrine 2015;48:916-923

26 Nanda N, Bobby Z, Hamide A: Oxidative stress in antithyroperoxidase antibody positive hypothyroid patients. Asian J Biochem 2012;7:54-58.

27 Dean RT, Fu S, Stocker R, et al: Biochemistry and pathology of radical-mediated protein oxidation. Biochem J 1997;324:1-18.

28 Pearce EN: Update in lipid alterations in subclinical hypothyroidism. J Clin Endocrinol Metab 2012;97:326-333.

29 Moser M, Buchberger W, Mayer H, et al: Influence of an iodine-drinking cure on the antioxidative status of diabetic patients. Wien Klin Wochenschr 1991;103:183-186.

30 Kurku H, Gencer A, Pirgon O, et al: Increased oxidative stress parameters in children with moderate iodine deficiency. J Pediatr Endocrinol Metab 2016;29:1159-1164.
Oxidative Stress in Non-Autoimmune Subclinical Hypothyroidism 